\title{
Impact of I/D polymorphism of $A C E$ gene on risk of development and course of chronic obstructive pulmonary disease
}

Radosław Mlak ${ }^{1,2}$, Iwona Homa-Mlak ${ }^{1,2}$, Tomasz Powrózek², Barbara Mackiewicz ${ }^{2}$, Marek Michnar², Paweł Krawczyk², Marcin Dziedzic ${ }^{3}$, Renata Rubinsztajn ${ }^{4}$, Ryszarda Chazan ${ }^{4}$, Janusz Milanowski², Teresa Małecka-Massalska ${ }^{1}$

${ }^{1}$ Department of Human Physiology, Medical University of Lublin, Lublin, Poland ${ }^{2}$ Department of Oncology, Medical University of Lublin, Lublin, Poland

${ }^{3}$ Department of Laboratory Diagnostics, Medical University of Lublin, Lublin, Poland ${ }^{4}$ Department of Internal Medicine, Pulmonology and Allergology, Medical University of Warsaw, Warsaw, Poland

Submitted: 12 June 2014

Accepted: 10 September 2014

Arch Med Sci 2016; 12, 2: 279-287

DOI: 10.5114 /aoms.2015.50757

Copyright (C) 2016 Termedia \& Banach

\section{Abstract}

Introduction: Chronic obstructive pulmonary disease (COPD) affects more than $10 \%$ of the world's population over 40 years of age. The main exogenous risk factor is cigarette smoking; however, only $20 \%$ of smokers develop COPD, indicating that some other factors, e.g. genetic, may play an important role in the disease pathogenesis. Recent research indicates that ACE (angiotensin-converting enzyme) may be a susceptibility gene for asthma or COPD. The aim of our study was to determine the influence of I/D (insertion/deletion) polymorphism of the ACE gene (AluYa5, rs4646994) on the risk and course of COPD.

Material and methods: We investigated ACE I/D polymorphism in 206 COPD and 165 healthy Caucasian subjects.

Results: In the generalized linear model (GLZ) analysis of the influence of selected factors on presence of COPD we found a significant independent effect for male sex (repeatedly increases the risk of COPD, OR $=7.7$, $p=0.049)$, as well as smoking or lower body mass index, but only in combination with older age $(\mathrm{OR}=0.96, p=0.003$ and $\mathrm{OR}=1.005, p=0.04$ respectively). Interestingly, analysis of factors which may influence the risk of a higher number of exacerbations demonstrated that occurrence of DD genotype, but only in men, is associated with a lower risk $(O R=0.7$, $p=0.03)$ of this complication.

Conclusions: We suggest that $A C E$ may not be a susceptibility gene for the origin of COPD but a disease-modifying gene. Since the impact of I/D polymorphism of the ACE gene on COPD risk is moderate or negligible, other molecular changes, that will help predict the development of this disease, should still be sought.

Key words: chronic obstructive pulmonary disease, $A C E$ polymorphism, exacerbation, renin-angiotensin-aldosterone system.

\section{Introduction}

Chronic obstructive pulmonary disease (COPD) affects more than $10 \%$ of the world's population over 40 years of age. The disease occurs more frequently in men; however, this difference is constantly decreasing

\author{
Corresponding author: \\ Radosław Mlak PhD \\ Department \\ of Human Physiology \\ Medical University \\ of Lublin \\ 11 Radziwiłłowska St \\ 20-080 Lublin, Poland \\ Phone: +48 815288430 , \\ +48 507250968 \\ Fax: +48 815288434 \\ E-mail: \\ radoslaw.mlak@gmail.com
}


(probably due to the increasing number of women who smoke), as has been noted in the past few years [1, 2]. Chronic obstructive pulmonary disease can be defined in several ways: historically as chronic bronchitis, anatomically as emphysema and pathophysiologically as airway obstruction. Despite the fact that COPD affects the lungs, it can refer to the function of the whole body (multi-organ abnormalities: cardiac disease, osteoporosis, skeletal disorders, neurological impairment and systemic inflammation). According to the gold standard, diagnosis of COPD should be based on evaluation of the clinical history of the patients and results of pulmonary function tests (PFTs) [3]. The disease is characterized by progressive and non-fully reversible airway obstruction. Obstructions stems from a disease of the small airways and destruction of lung parenchyma (emphysema) of varying severity.

This is most commonly associated with an abnormal inflammatory response of the respiratory system to harmful dust and substances. The main exogenous risk factor of COPD is cigarette smoking (about $80 \%$ of cases) [1-3]. However, in the population of long-term smokers, only $20 \%$ develop COPD, which indicates that some other factors (e.g. genetic) may play an important role in disease pathogenesis. To date, the most widely known is the impact of inherited deficiency of $\alpha 1$ antitrypsin, which causes emphysema in COPD and asthma [4]. However, it seems most likely that COPD has a polygenic background. Genetic factors potentially associated with the development of COPD also include abnormalities in transforming growth factor $\beta 1$ (TGF- $\beta 1$ ) and microsomal epoxide hydrolase $(m E P H X)$ genes $[5,6]$. There is evidence that matrix metalloproteinase 1 and 12 gene (MMP1 and MMP12) polymorphisms correlate with more rapid progression of the disease [4]. Despite the progress of science, the basic mechanisms of pathogenesis of COPD are still not fully understood. It is still unclear which genes can participate in development of the disease, as well as in exacerbations and deterioration of lung function in COPD.

Recent research indicates that the renin-angiotensin-aldosterone system (RAAS) plays an important role in the pathogenesis in pulmonary and extrapulmonary manifestations of this disease. The RAAS induces pro-inflammatory mediators in the lung: interleukin-6 (IL-6), monocyte chemotactic protein-1 (MCP-1) and tumor necrosis factor- $\alpha$ (TNF- $\alpha$ ), which modulates process such as vascular remodeling fibroblast proliferation, oxidative stress and epithelial cell apoptosis [7]. Angiotensin-converting enzyme (ACE) plays an active role in the proper functioning of the RAAS - it catalyzes the conversion of inactive Angl (angio- tensin I) to the active form - Angll (angiotensin II) [8-10]. According to the data of the National Center for Biotechnology Information (NCBI), 160 polymorphisms of the human ACE gene (located on the long arm of chromosome 17 [17q23]) are known; most of them are single nucleotide polymorphisms (SNPs), 34 of them are located in the coding region; and 18 of them result in a change of amino acids in the protein $[4,8]$. There are at least 3 different alu elements in intron 16 of the $A C E$ gene, and these repetitive sequences may have different length (bp - number of base pairs), e.g.: 285 bp (AluSc), 288 bp (AluYa5, some authors describe this change as $287 \mathrm{bp}$ or $289 \mathrm{bp}$ ), 294 bp (AluYb8) [11, 12]. However, the most widely described polymorphism of the $A C E$ gene is a functional polymorphism, which is consequence of I/D (insertion or deletion) of 288 bp (AluYa5, dbSNP on NCBI website: rs4646994, GenBank: X62855.1), which results in various ACE activity. This polymorphism is responsible for $47 \%$ of observed changes (phenotypic differences) in the level of serum concentration of ACE protein. ACE activity is increased in homozygotes for the DD genotype, intermediate in heterozygotes (ID) and decreased in homozygotes for I (II) [13]. Some investigators suggest that functional polymorphism of the ACE gene may change ACE activity, so it may subsequently lead to increased susceptibility to pulmonary hypertension, asthma and COPD $[4,14]$. On the other hand, another study showed that changes in ACE activity may have an altering effect on the course of COPD [15].

The aim of our study was to determine the influence of I/D polymorphism (AluYa5, rs4646994) of the $A C E$ gene on the risk of development and course of COPD.

\section{Material and methods}

\section{Study population}

Prior to the study, the approval of the Ethics Committee of the Medical University of Lublin was obtained. Written informed consent was obtained from each patient/volunteer prior to their recruitment to the study. Recruitment and assessment of COPD patients and healthy volunteers are shown in Figure 1.

This study was conducted from June 2010 to July 2012. The investigated Caucasian population consisted of 206 COPD patients (treated in the Department of Pneumonology, Oncology and Allergology, Medical University of Lublin and the Department of Internal Medicine, Pulmonology and Allergology, Medical University of Warsaw) and 165 healthy volunteers (control group). Baseline characteristics of COPD patients and the control group are presented in Table I. The pack-years val- 
303 COPD patients invited

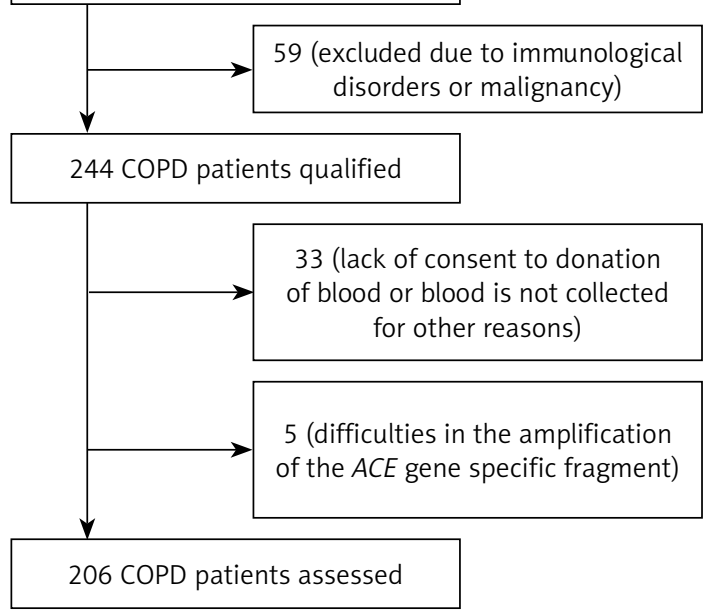

Figure 1. Flow chart of recruitment and assessment

ue was calculated as the number of cigarette packs smoked per day multiplied by the number of years. The diagnosis of COPD was established according to the guidelines of the ATS/ERS (American Thoracic Society/European Respiratory Society) [16]. Patients were staged according to Global Initiative for Chronic Obstructive Lung Disease (GOLD) criteria. Exacerbations were defined (according to ATS/ERS criteria) as sudden deterioration in the patient's condition which was an indication for hospitalization and concerned simultaneous occurrence of three symptoms - intensification of dyspnea, cough and expectoration. Throughout the duration of the study, patients used shortor long-acting anticholinergic drugs. If necessary additional long-acting $\beta_{2}$-agonists (LABA) and/ or inhaled steroids were used. In order to more adequately assess the impact of the ACE gene polymorphism on the development and course of COPD the effect of tobacco smoking was reduced through the inclusion in both groups (control and COPD) of mainly smokers.

All healthy volunteers denied a history of systemic, respiratory or other system diseases. Moreover, in COPD patients 6-minute walking test (6MWT) and evaluation of parameters such as blood pressure, saturation, forced expiratory volume in $1 \mathrm{~s}\left(\mathrm{FEV}_{1}\right)$ and Tiffeneau index (forced expiratory volume in $1 \mathrm{~s}$ as \% of vital capacity - FEV ${ }_{1} /$ FVC) before and after this test was performed. Forced spirometry was performed in accordance with ATS/ERS standardization (general considerations for lung function testing, three consecutive measurements were taken and the best value was recorded) guidelines.

Mean age in the COPD and control group was 66.2 and 55.1 years respectively. In the studied populations $68 \%$ and $63 \%$ of subjects, respectively, were men. Median value of body mass index

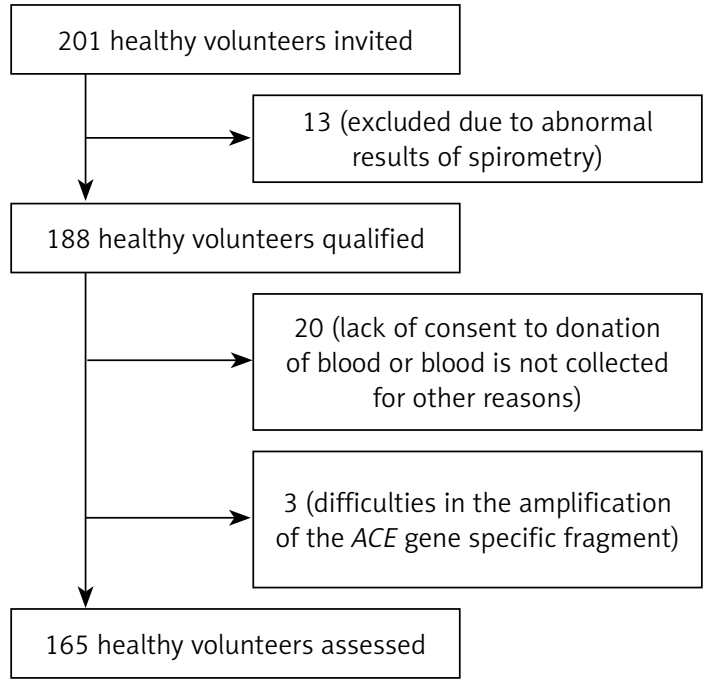

(BMI) was 26 in COPD patients and 27.7 in healthy subjects. The median pack-years value was 39.5 and 44 respectively. Extended clinical characteristics of COPD patients are presented in Table II. The COPD patients' median $\mathrm{FEV}_{1}$ and $\mathrm{FEV}_{1} / \mathrm{FVC}$ were $45 \%$ of reference and $49 \%$ respectively. Disease stage I or II was diagnosed in $38.8 \%$, III in $44.2 \%$ and IV in $17 \%$ of patients. Frequent COPD exacerbations ( $\geq 3$ per year) occurred in $21.8 \%$ of patients.

Patients with severe medical disorders including immunological disorders or malignancy were excluded from the study. All patients were at least 18 years old. Venous blood was collected from all patients/volunteers and genomic DNA was extracted according to the manufacturer's protocol using the Qiagen Blood Mini Kit (Qiagen, Germany).

\section{Assessment of ACE gene I/D polymorphism}

To evaluate quantity and quality of the isolated DNA we used the spectrophotometer BioPhotometer Plus with UV/VIS filters (Eppendorf, Germany). Polymerase chain reaction (PCR), leading to amplification of the DNA fragment containing the I/D ACE gene polymorphism was performed in a total volume of $20 \mu \mathrm{l}$ containing 20-40 ng of template DNA, $0.5 \mu \mathrm{M}$ of each primer, $0.2 \mathrm{mM}$ of each dNTP, $2.4 \mathrm{mM} \mathrm{MgCl}_{2}$ and $1.0 \mathrm{U}$ Taq polymerase with $1 \mathrm{X}$ Reaction buffer (Fermentas, Burlington, Canada). We used independently designed specific primers - forward: 5'-CTG GAG AGC CAC TCC CAT CCT TCT-3' and reverse: 5'-GAC GTG GCC ATC ACA TTC GTC AGA TC-3', which flank the polymorphic site. PCR amplification was carried out in a T Personal thermocycler (Biometra, Göttingen, Germany) in the following conditions: initial denaturation at $96^{\circ} \mathrm{C}$ for $15 \mathrm{~min}$, followed by 33 cycles of: $30 \mathrm{~s}$ at $96^{\circ} \mathrm{C}, 120 \mathrm{~s}$ at $61^{\circ} \mathrm{C}$ and $60 \mathrm{~s}$ at $72^{\circ} \mathrm{C}$ and end 
R. Mlak, I. Homa-Mlak, T. Powrózek, B. Mackiewicz, M. Michnar, P. Krawczyk, M. Dziedzic, R. Rubinsztajn, R. Chazan, J. Milanowski, T. Małecka-Massalska

Table I. Baseline demographic, clinical and genetic characteristics of COPD patients and healthy volunteers

\begin{tabular}{|c|c|c|c|}
\hline Factor & $\begin{array}{l}\text { Control } \\
(n=165)\end{array}$ & $\begin{array}{c}\text { COPD } \\
(n=206)\end{array}$ & $\begin{array}{c}\text { OR } \\
95 \% \mathrm{Cl} \\
Z \text { statistic } \\
P \text {-value }\end{array}$ \\
\hline Gender: & & & $\begin{array}{c}0.80 \\
0.52-1.24\end{array}$ \\
\hline Male & $104(63 \%)$ & $140(68 \%)$ & 0.99 \\
\hline Female & $61(37 \%)$ & $66(32 \%)$ & 0.32 \\
\hline \multicolumn{4}{|l|}{ Age [years]: } \\
\hline Median & 67 & 65 & -0.1 \\
\hline Mean (range) & $64(29-92)$ & $63(32-85)$ & 0.9 \\
\hline Stand. dev. & 10.6 & 9.4 & \\
\hline $\mathrm{BMI}\left[\mathrm{kg} / \mathrm{m}^{2}\right]:$ & 27.7 & 26 & \\
\hline Median mean (range) & $28.4(15.2-49)$ & $27(17-43)$ & -1.9 \\
\hline Stand. dev. & 5.9 & 5.6 & 0.1 \\
\hline \multicolumn{4}{|c|}{ Smoking history [pack-years]: } \\
\hline Median & 44 & 39.5 & 0.6 \\
\hline Mean (range) & $43.3(1-110)$ & $41.5(4-170)$ & 0.6 \\
\hline Stand. dev. & 24.5 & 20.2 & \\
\hline Smoking: & & & $\begin{array}{c}1.34 \\
0.61-2.92\end{array}$ \\
\hline Smokers & $154(93.3 \%)$ & $188(91.3 \%)$ & 0.74 \\
\hline Non-smokers & $11(6.7 \%)$ & $18(8.7 \%)$ & 0.46 \\
\hline \multicolumn{4}{|l|}{ ACE genotype: } \\
\hline $\mathrm{DD}$ & $51(30.9 \%)$ & $60(29.1 \%)$ & 0.5 \\
\hline ID & $73(44.2 \%)$ & $99(48.1 \%)$ & 0.8 \\
\hline II & $41(24.9 \%)$ & $47(22.8 \%)$ & \\
\hline \multirow[t]{3}{*}{$\begin{array}{l}\text { DD } \\
\text { ID or II }\end{array}$} & & & $\begin{array}{c}1.09 \\
0.70-1.70\end{array}$ \\
\hline & $51(30.9 \%)$ & $60(29.1 \%)$ & 0.37 \\
\hline & $114(69.1 \%)$ & $146(70.9 \%)$ & 0.71 \\
\hline \multirow[t]{3}{*}{$\begin{array}{l}\text { ID } \\
\text { II or DD }\end{array}$} & & & $\begin{array}{c}0.86 \\
0.57-1.29 \\
\end{array}$ \\
\hline & $73(44.2 \%)$ & $99(48.1 \%)$ & 0.73 \\
\hline & $92(55.8)$ & $107(51.9 \%)$ & 0.46 \\
\hline \multirow[t]{3}{*}{$\begin{array}{l}\text { II } \\
\text { ID or DD }\end{array}$} & & & $\begin{array}{c}1.12 \\
0.69-1.81\end{array}$ \\
\hline & $41(24.8 \%)$ & $47(22.8 \%)$ & 0.46 \\
\hline & $124(75.2 \%)$ & $159(77.2 \%)$ & 0.65 \\
\hline
\end{tabular}

$B M I$ - body mass index, DD - deletion/deletion genotype, ID - insertion/deletion genotype, II - insertion/insertion genotype, stand. dev. - standard deviation, OR - odds ratio, $95 \% \mathrm{Cl}$ - confidence interval, Z statistic. Selection of appropriate statistics depend on the nature of the variables (discrete, continuous). 
with a final elongation step of $10 \mathrm{~min}$ at $72^{\circ} \mathrm{C}$. For the separation of the PCR products we used horizontal electrophoresis ( $2 \%$ agarose gel with use of ethidium bromide in TBE buffer environment). After electrophoresis, the DNA bands were visualized with UV light of a transilluminator. In the present study we investigated I/D polymorphism (AluYa5, rs4646994) of the ACE gene. In the tested site a 288 bp fragment (of intron 16) is inserted or removed. In the case of homozygous genotypes I/I and D/D, one band was observed at respectively 480 or 192 bp. In heterozygous samples (I/D) both bands occurred simultaneously (Figure 2).

\section{Statistical analysis}

All statistical analysis was performed using the statistical software Statistica 10 (StatSoft, USA). The $\chi^{2}$ test was used to determine the Hardy-Weinberg equilibrium of ACE genotypes as well as differences in frequency distribution of selected demographic, clinical and molecular factors in the COPD and control group. The statistician who performed the calculation in the present paper was Paprzycki. Effects of these factors on the COPD risk were assessed using a complete and optimal generalized linear model (GLZ). In the constructed model, the effects of all predictors and all second-order interactions (binomial distribution, binding variable - logit) were included. The influence of selected demographic, clinical and molecular factors on occurrence of COPD exacerbations and predisposition to a certain severity of COPD (GOLD stages) was evaluated using complete and optimal GLZ (Poisson distribution, binding function - log; ordinal multinomial distribution, binding function - logit respectively). Interactions of measurable (e.g., age) and unmeasurable (e.g. sex) data obtained on the basis of GLZ analysis should be interpreted in the following way: if the interaction of gender (male) and disease duration (in years) is evaluated, it should be understood that: in men with each passing year of the disease, risk of exacerbations of COPD is increased/ decreased by the odds ratio (OR) value specified in text or tables. Evaluation of the relationship between sex, ACE polymorphisms and stages of COPD was performed using the Pearson $\chi^{2}$ test in log linear analysis. When the influence of studied factors was evaluated, OR and the 95\% confidence interval $(95 \% \mathrm{Cl})$ were calculated. A level of $p$-value less than 0.05 was assigned as significant.

\section{Results}

Characteristics of patients and healthy volunteers and frequency of ACE genotypes

There was no statistically significant difference in sex, age, BMI, smoking history or genotype or
Table II. Extended clinical characteristics of COPD patients

\begin{tabular}{|c|c|}
\hline Factor & $\begin{array}{l}\text { Median, mean (range), } \\
\text { standard deviation }\end{array}$ \\
\hline \multicolumn{2}{|l|}{ Blood pressure [mm Hg]: } \\
\hline Systolic & 120, 121.9 (80-190), 19.2 \\
\hline Diastolic & $70,73.1(50-115), 11.5$ \\
\hline Saturation before drug (\%) & $95,93.8$ (50-98), 4.3 \\
\hline $\mathrm{FEV}_{1}$ before drug (\%) & $45,45.4$ (16-87), 15.6 \\
\hline $\begin{array}{l}\mathrm{FEV}_{1} / \mathrm{FVC} \text { before drug } \\
\text { (\% ratio) }\end{array}$ & $49,48.3$ (19-70), 12 \\
\hline 6MWT distance $[\mathrm{m}]$ & 420, 411.1 (120-750), 120.9 \\
\hline \multicolumn{2}{|c|}{ Blood pressure after $6 \mathrm{MWT}$ [mm Hg]: } \\
\hline Systolic & 140, 143 (75-219), 25.1 \\
\hline Diastolic & $77.5,76.0(50-110), 12.4$ \\
\hline $\begin{array}{l}\text { Saturation, } \\
\% \text { after } 6 \mathrm{MWT}[\mathrm{m}]\end{array}$ & 91, 89.8 (67-98), 5.8 \\
\hline $\mathrm{FEV}_{1}, \%$ after drug & $57,55.9$ (3-104.5), 19.8 \\
\hline $\begin{array}{l}\mathrm{FEV}_{1} / \mathrm{FVC} \\
\% \text { ratio after drug }\end{array}$ & $57,59.48(1-121), 22.4$ \\
\hline
\end{tabular}

6MWT - 6-minute walk test, FEV - forced expiratory volume in $1 \mathrm{~s}$, $F E V_{1} / F V C$ - forced expiratory volume in $1 \mathrm{~s} /$ forced vital capacity.

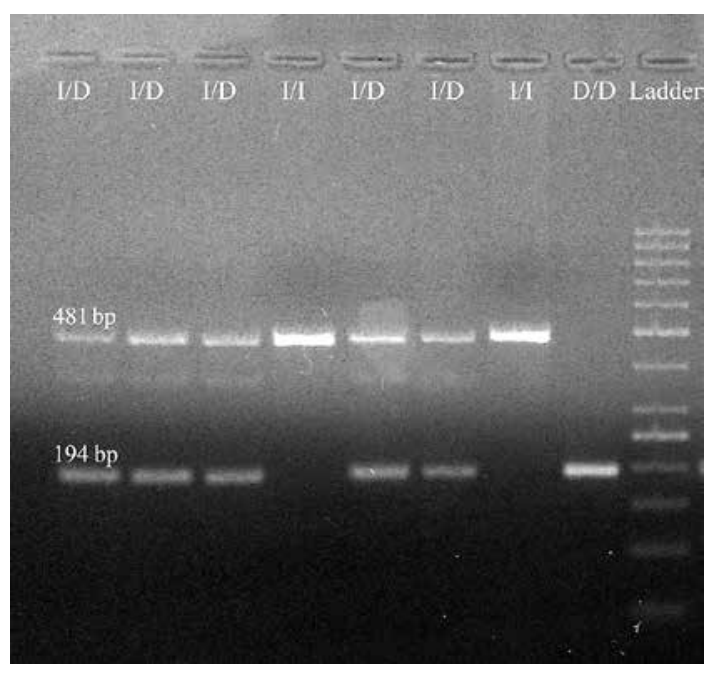

Figure 2. Representative electropherogram and analysis of ACE I/D polymorphism

$D D$ - deletion/deletion genotype, ID - insertion/deletion genotype, II - insertion/insertion genotype, bp - base pair.

allele frequency distribution between the COPD and control group (Table I). Extended clinical characteristics of COPD patients are shown in Table II. Frequencies of DD, ID or DD genotypes and D or I allele positivity of the ACE gene in the study (29.1\%, $48.1 \%, 22.8 \%$ and $53.2 \%$ or $46.8 \%$ respectively) and healthy volunteer group (30.9\%, 44.2\%, $24.8 \%$ and $53.0 \%$ or $47.0 \%$ respectively) are shown 
in Table I. The distribution of polymorphic variants of $A C E$ was in Hardy-Weinberg equilibrium for both the study $\left(\chi^{2}=2.1, p=0.8\right)$ and the control group $\left(\chi^{2}=0.2, p=0.4\right)$. There was no statistically significant difference in ACE genotype distribution between the COPD and control group. Moreover, no statistically significant difference in ACE genotype distribution (in either the male or female subgroup) according to various stages of COPD was observed (Table III). In the GLZ analysis of the influence of selected factors on presence of COPD (Table IV) we found a statistically significant independent effect for male sex (repeatedly increases the risk of COPD, $\mathrm{OR}=7.7, p=0.049$ ), as well as smoking or lower $\mathrm{BMI}$, but only in combination with older age $(\mathrm{OR}=$ $0.9, p=0.003$ and $\mathrm{OR}=1.005, p=0.04$ respectively). However, there was no statistically significant effect of $A C E$ genotype. After rejecting predictors adding no significant contribution to the model (optimal model, $\chi^{2}=374.2 ; \mathrm{AIC}=420.7 ; \mathrm{BIC}=$ 440.2), significant effects of smoking $(\mathrm{OR}=12.4$, $p=0.0004)$, lower $\mathrm{BMI}(\mathrm{OR}=0.9, p=0.004)$ as well as combinations of smoking $(\mathrm{OR}=0.9, p=0.0006)$ or lower $\mathrm{BMI}(\mathrm{OR}=1.002, p<0.0001)$ with older age were obtained.

In the analysis of the impact of selected factors on higher number of COPD exacerbations (Table V) a statistically significant independent effect of increasing the distance in the 6MWT (OR $=0.9$, $p<0.0001)$ or a combination of factors such as male sex and DD genotype of the ACE gene $(\mathrm{OR}=0.7, p=0.03)$ was found. In the optimal model $\left(\chi^{2}=336.4 ; \mathrm{AIC}=576.5 ; \mathrm{BIC}=585.7\right)$, significant effects of older age $(\mathrm{OR}=0.9, p=0.02)$ and increasing the distance in the 6MWT $(\mathrm{OR}=0.9, p<0.0001)$ were observed.

\section{Discussion}

The originality of our results is the demonstration of the relationship between ACE gene polymorphism and the course of COPD, which has not been presented by other authors.

Circulating (endocrine) ACE regulated by RAAS plays a key role in long-term control of blood volume and pressure. Renin is produced and released by kidneys under conditions of abnormal salt level, volume loss or sympathetic stimulation. Renin converts the inactive angiotensinogen (synthesized in the liver) to angiotensin I, which has vasoactive properties. Subsequently, angiotensin I is trans formed to angiotensin II (a powerful and effective vasoconstrictor) with the participation of ACE. Moreover, it exerts its effect on the adrenal cortex through increased secretion of aldosterone. This process promotes reabsorption of sodium and water from the urine. Beside direct effects, which are aimed at increasing the volume of fluid and blood pressure, angiotensin II also regulates cell proliferation and growth. Angiotensin II may also induce endothelial dysfunction by reducing nitric oxide bioavailability. ACE also plays a significant role in other hormonal systems, e.g. the kinin-kallikrein cascade. It influences the metabolism of bradykinin, which is a potent vasodilator. Thus, it plays a key role in blood pressure control also through this pathway. Moreover, it may influence muscle metabolism, oxygenation and its endurance [17].

Functional polymorphism of the $A C E$ gene may change ACE activity and may subsequently lead to increased susceptibility for pulmonary hypertension, asthma and COPD $[4,13,18]$. Besides the impact on the risk of development of the above diseases, disorders of the ACE appear to influence their course [15]. Despite the several efforts to explain this problem, the impact of the $A C E$ gene polymorphism on the development of COPD is still not clearly defined. In contrast to numerous papers, in our study we demonstrate that none of polymorphic variants of the ACE gene is significantly associated with an increased risk of COPD. Pabst et al. on the basis of their results showed that homozygous I is associated with an increased risk of COPD. Busquets et al. noted significantly higher frequency of D/D homozygotes in smokers with COPD. They concluded that the polymorphism of the ACE gene is associated with a history of smoking as well as with the risk factor of COPD [4, 18]. Additionally, most researchers described DD genotype as a risk factor of COPD development $[19,20]$. These reports were evaluat-

Table III. Distribution of genotypes of ACE gene in different stages of COPD

\begin{tabular}{|c|c|c|c|c|c|c|}
\hline$A C E$ genotype & A, $n(\%)$ & B, $n(\%)$ & C, $n(\%)$ & D, $n(\%)$ & Total, $n$ & $\chi^{2} ; p$-value \\
\hline DD & $20(33.3)$ & 8 (13.3) & $24(40)$ & $8(13.4)$ & 60 & \multirow{3}{*}{$\begin{array}{l}10.9 \\
0.09\end{array}$} \\
\hline ID & $19(19.2)$ & $21(21.2)$ & $43(43.4)$ & $16(16.2)$ & 99 & \\
\hline II & $15(32)$ & $2(4.3)$ & $20(42.5)$ & $10(21.2)$ & 47 & \\
\hline Total & $54(26.3)$ & $31(15)$ & $87(42.2)$ & $34(16.5)$ & 206 & \\
\hline I & $34(23.3)$ & $23(15.8)$ & $63(43.1)$ & $26(17.8)$ & 146 & \multirow{2}{*}{$\begin{array}{l}0.7 \\
0.9\end{array}$} \\
\hline D & 39 (24.6) & $29(18.3)$ & $67(42.1)$ & $24(15)$ & 159 & \\
\hline
\end{tabular}

DD - deletion/deletion genotype, ID - insertion/deletion genotype, II - insertion/insertion genotype. 
Table IV. Influence of selected factors and second or third degree of their combination on the risk of COPD

\begin{tabular}{|c|c|c|c|c|c|}
\hline Factor & $w$ & OR & Rating & $(95 \% \mathrm{Cl})$ & $P$-value \\
\hline Intercept & 0.4 & - & 2.3 & $(-5.1-9.7)$ & 0.5 \\
\hline Gender (male) & 3.9 & 7.7 & 2.0 & $(0.01-4.07)$ & 0.049 \\
\hline Age (with every passing year) & 0.9 & 0.9 & -0.06 & $(-0.2-0.06)$ & 0.3 \\
\hline Smoking (with every pack-year) & 1.3 & 3.5 & 1.2 & $(-0.8-3.4)$ & 0.2 \\
\hline DD genotype & 1.4 & 5.7 & 1.7 & $(-1.2-4.6)$ & 0.2 \\
\hline II genotype & 1.5 & 0.1 & -2.2 & $(-5.6-1.2)$ & 0.2 \\
\hline ID genotype & 0.1 & 1.6 & 0.5 & $(-2.2-3.2)$ & 0.7 \\
\hline Gender (male) and age (with every passing year) & 2.6 & 0.9 & -0.02 & $(-0.04-0.004)$ & 0.1 \\
\hline Gender (male) and BMI (decrease, with every unit) & 0.6 & 0.9 & -0.02 & $(-0.07-0.03)$ & 0.4 \\
\hline Gender (male) and smokers & 0.8 & 0.8 & -0.1 & $(-0.4-0.2)$ & 0.3 \\
\hline Gender (male) and DD genotype & 0.5 & 1.1 & 0.1 & $(-0.3-0.5)$ & 0.5 \\
\hline Gender (male) and II genotype & 0.005 & 0.9 & -0.01 & $(-0.45-0.4)$ & 0.9 \\
\hline $\begin{array}{l}\text { Age (with each passing year) and smoking } \\
\text { (with each pack-year) }\end{array}$ & 8.7 & 0.96 & -0.03 & $(-0.06)-(-0.01)$ & 0.003 \\
\hline $\begin{array}{l}\text { Age (with each passing year) and BMI } \\
\text { (decrease, with every unit) }\end{array}$ & 4.3 & 1.005 & 0.005 & $(0.0003-0.009)$ & 0.04 \\
\hline Age (with each passing year) and DD genotype & 1.6 & 0.9 & -0.02 & $(-0.06-0.01)$ & 0.19 \\
\hline Age (with each passing year) and II genotype & 1.4 & 1.02 & 0.02 & $(-0.01-0.06)$ & 0.2 \\
\hline Smokers and BMI (decrease, with every unit) & 2.3 & 1.04 & 0.04 & $(-0.01-0.09)$ & 0.1 \\
\hline Smoking (with every pack-year) and DD genotype & 1.04 & 0.8 & -0.2 & $(-0.6-0.19)$ & 0.3 \\
\hline Smoking (with every pack-year) and II genotype & 1.5 & 1.3 & 0.3 & $(-0.2-0.7)$ & 0.2 \\
\hline BMI (decrease, with every unit) and DD genotype & 0.2 & 0.9 & -0.01 & $(-0.08-0.05)$ & 0.6 \\
\hline BMI (decrease, with every unit) and II genotype & 0.5 & 1.03 & 0.03 & $(-0.05-0.1)$ & 0.5 \\
\hline Model fit statistics & \multicolumn{5}{|c|}{ Pearson's $\chi^{2}=329.8 ; \mathrm{AIC}=620.6 ; \mathrm{BIC}=690.9$} \\
\hline
\end{tabular}

AIC - Akaike's information criterion, BIC - Bayesian information criterion, BMI - body mass index, DD - deletion/deletion genotype, $I D$ - insertion/deletion genotype, II - insertion/insertion genotype, $W$ - Wald statistic, OR-odds ratio, $\mathrm{Cl}$ - confidence interval.

ed in two meta-analyses [21, 22]. Both papers indicate that DD genotype is a risk factor of COPD in Asian but not in Caucasian/European populations, which is consistent with our results.

There are several possible reasons for these discrepancies. It is well known that the origin of the population subject to genetic differences is responsible for the number of discrepancies in the risk of development and the course of many diseases. Other factors such as the environment or smoking habits may also play a significant role in determining these differences.

Currently, there are numerous papers linking ACE DD genotype with increased activity of the encoded protein and its influence on COPD course $[4,13]$. However, some studies do not confirm this finding and suggest that an influence of DD genotype on the course of the disease other than previously described is possible [19, 23, 24]. Thus the mechanism leading to this observation is still not fully understood. Interestingly, analysis of factors which may influence the risk of a higher number of exacerbations in COPD demonstrated that occurrence of DD genotype, but only in men, is associated with a lower risk of prevalence of this type of disease complication. Furthermore, in these men (DD homozygotes) lower risk of more severe disease occurred. Opposite to our results, Pabst et al. found that patients (regardless of sex) with a diagnosed $A C E$ I allele were characterized by significantly more common occurrence of stable COPD [4]. Sex substantially modulates the risk of morbidity in many diseases (including cardiovascular and respiratory, inter alia COPD). Although the main objective of the study was to assess the relationship between I/D polymorphism of the $A C E$ gene and the risk and course of COPD during data analysis, we found that the 6MWT distance 
R. Mlak, I. Homa-Mlak, T. Powrózek, B. Mackiewicz, M. Michnar, P. Krawczyk, M. Dziedzic, R. Rubinsztajn, R. Chazan, J. Milanowski, T. Małecka-Massalska

Table V. Influence of selected factors and their second degree combinations on the risk of COPD exacerbations

\begin{tabular}{|c|c|c|c|c|c|}
\hline Factor & $w$ & OR & Rating & $(95 \% \mathrm{Cl})$ & $P$-value \\
\hline Intercept & 0.1 & - & 1.05 & $(-5.6-7.7)$ & 0.8 \\
\hline Gender (male) & 0.7 & 1.1 & 0.1 & $(-0.1-0.4)$ & 0.4 \\
\hline Age (with every passing year) & 3.0 & 0.9 & -0.01 & $(-0.03-0.002)$ & 0.08 \\
\hline BMI (decrease, with every unit) & 2.2 & 0.9 & -0.02 & $(-0.05-0.007)$ & 0.1 \\
\hline Smoking (with every pack-year) & 1.7 & 0.9 & -0.004 & $(-0.01-0.002)$ & 0.2 \\
\hline $\mathrm{FEV}_{1}$ before drug (with every $1 \%$ ) & 0.02 & 0.9 & -0.09 & $(-1.2-1.03)$ & 0.9 \\
\hline $\mathrm{FEV}_{1}$ after drug (with every $1 \%$ ) & 0.4 & 0.7 & -0.3 & $(-1.4-0.7)$ & 0.5 \\
\hline Saturation before 6MWT (with every 1\%) & 0.5 & 0.9 & -0.01 & $(-0.05-0.03)$ & 0.5 \\
\hline Saturation after 6MWT (with every 1\%) & 2.8 & 1.03 & 0.03 & $(-0.005-0.07)$ & 0.09 \\
\hline Hypertension (presence) & 0.08 & 0.9 & -0.04 & $(-0.3-0.2)$ & 0.8 \\
\hline 6MWT (increase of distance, with every $1 \mathrm{~m}$ ) & 16.3 & 0.9 & -0.003 & $(-0.004)-(-0.001)$ & 0.0001 \\
\hline $\begin{array}{l}\text { Blood pressure before/after } 6 \mathrm{MWT} \text { (increase of each } \\
1 \mathrm{~mm} \mathrm{Hg} \text { ) }\end{array}$ & 0.01 & 1.0004 & 0.0005 & $(-0.007-0.008)$ & 0.9 \\
\hline DD genotype & 1.01 & 1.2 & 0.2 & $(-0.1-0.5)$ & 0.3 \\
\hline II genotype & 0.1 & 0.9 & -0.06 & $(-0.4-0.3)$ & 0.7 \\
\hline Male gender and DD genotype & 5.5 & 0.7 & -0.4 & $(-0.7)-(-0.06)$ & 0.03 \\
\hline Male gender and II genotype & 3.3 & 1.4 & 0.3 & $(-0.03-0.7)$ & 0.07 \\
\hline Male gender and hypertension & 0.01 & 0.9 & -0.01 & $(-0.3-0.2)$ & 0.9 \\
\hline DD genotype and hypertension & 0.04 & 0.9 & -0.03 & $(-0.3-0.3)$ & 0.8 \\
\hline II genotype and hypertension & 1.1 & 1.2 & 0.2 & $(-0.1-0.5)$ & 0.3 \\
\hline Male gender and DD genotype and hypertension & 2.8 & 0.8 & -0.3 & $(-0.6-0.05)$ & 0.09 \\
\hline Male gender and II genotype and hypertension & 0.6 & 1.1 & 0.1 & $(-0.2-0.5)$ & 0.4 \\
\hline Model fit statistics & \multicolumn{5}{|c|}{ Pearson's $\chi^{2}=364.0 ; \mathrm{AIC}=439.6 ; \mathrm{BIC}=521.5$} \\
\hline
\end{tabular}

6MWT - 6-minute walk test, AIC - Akaike's information criterion, BIC - Bayesian information criterion, DD - deletion/deletion genotype, FEV 1 - forced expiratory volume in one second, II - insertion/insertion genotype, $W$ - Wald statistic, OR - odds ratio, CI - confidence interval.

has a strong impact on the exacerbation risk in COPD patients. An increase by 1 meter of distance in the 6 MWT was associated with a $10 \%$ reduction in the risk of a greater number of COPD exacerbations during the year. These results are consistent with the findings of other authors, who have also demonstrated that tolerance to effort assessed by determining the distance in the 6MWT can predict the risk of exacerbations in patients with COPD. The ability to exercise is one of the most important factors to be considered in predicting the course of COPD, because exercise tolerance decreases as the disease progresses [25]. Decrease in physical activity, which can be demonstrated by a reduction in 6MWT distance, results in a higher probability of new exacerbations and more frequent hospitalization. Reduced exercise tolerance, characteristic of patients with COPD, indirectly affects the decrease in survival $[26,27]$.
In our study there were no statistically significant differences in sex, age, BMI, smoking history or genotype or allele frequency distribution between the COPD and control group, which may be caused by the small sample size and heterogeneity of the analyzed groups. Another limitation of our study was the lack of pulmonary function data in the control group. Data were also not stratified by variables such as $\mathrm{PaCO}_{2}, \mathrm{PaO}_{2}, \mathrm{SaO}_{2}$ and complication of COPD in patients. It is also possible that other unknown confounding factors may have influenced the associations, including subclinical disease, which was not detectable through the analysis of lipids, glycemia and hypertension. However, it is unlikely that the presence of vascular disorders has influenced our results; associations remained significant after controlling for vascular factors or excluding persons with ischemic pathologies. It seems that DD genotype of 
the ACE gene protects against muscle fatigue and the patients have better ventilation. This observation is in line with reported advantages of DD genotype on muscular training effects. However, these data should be confirmed in further studies to avoid a bias due to the baseline limitation imposed by $\mathrm{FEV}_{1}$ decrease and BMI.

On the basis of our results, we suggest that the effect of $A C E$ gene polymorphism on the course of COPD may be dependent on gender. We suggest that $A C E$ may not be a susceptibility gene for the origin of COPD but a disease-modifying gene. Since the impact of I/D polymorphism of the $A C E$ gene on COPD risk is moderate or negligible, other molecular changes, that will help predict the development of this disease, should still be sought. Despite this, there is a potential utility for analysis of ACE ID polymorphism in the near future, because the determination of such polymorphism may be a useful tool in prediction of the COPD course and may have an influence on the treatment and surveillance of COPD patients. To confirm our findings, further investigations with a larger group of patients should be performed.

\section{Conflict of interest}

The authors declare no conflict of interest.

\section{References}

1. Wozniak K, Sleszycka J, Safianowska A, Wiechno W, Domagala-Kulawik J. Systemic inflammation in peripheral arterial disease with or without coexistent chronic obstructive pulmonary disease: analysis of selected markers. Arch Med Sci 2012; 8: 477-83.

2. Serapinas D, Sitkauskiene B, Sakalauskas R. Inflammatory markers in chronic obstructive pulmonary disease patients with different alpha1 antitrypsin genotypes. Arch Med Sci 2012; 8: 1053-8.

3. Yawn BP. Is 'GOLD' standard for the management of COPD in clinical practice? Drugs Context 2012; 2012: 212243.

4. Pabst S, Theis B, Gillissen A, et al. Angiotensin-converting enzyme I/D polymorphism in chronic obstructive pulmonary disease. Eur J Med Res 2009; 14: 177-81.

5. Bossé Y. Updates on the COPD gene list. Int J Chron Obstruct Pulmon Dis 2012; 7: 607-31.

6. Xiao M, Guo L, Wang T, et. al. Interleukin-1B-31T/C promoter polymorphism and chronic obstructive pulmonary disease risk: a meta-analysis. Arch Med Sci 2014; 10: 434-8.

7. Shrikrishna D, Astin R, Kemp PR, Hopkinson NS. Reninangiotensin system blockade: a novel therapeutic approach in chronic obstructive pulmonary disease. Clin Sci 2012; 123: 487-98.

8. Crowley SD, Coffman TM. Recent advances involving the renin-angiotensin system. Exp Cell Res 2012; 318: 1049-56.

9. Puthucheary Z, Skipworth JR, Rawal J, Loosemore M, Van Someren K, Montgomery HE. The ACE gene and human performance: 12 years on. Sports Med 2011; 41: 433-48.
10. Richard PM. The pulmonary renin-angiotensin system. Curr Pharm Des 2003; 9: 715-22.

11. Rieder MJ, Taylor SL, Clark AG, Nickerson DA. Sequence variation in the human angiotensin converting enzyme. Nat Genet 1999; 22: 59-62.

12. Lei H, Day IN, Vorechovský I. Exonization of AluYa5 in the human ACE gene requires mutations in both $3^{\prime}$ and 5' splice sites and is facilitated by a conserved splicing enhancer. Nucleic Acids Res 2005; 33: 3897-906.

13. Rigat B, Hubert C, Alhenc-Gelas F, Cambien F, Corvol P, Soubrier F. An insertion/deletion polymorphism in the angiotensin I-converting enzyme gene accounting for half the variance of serum enzyme levels. J Clin Invest 1990; 86: 1343-6.

14. Kieszko R, Krawczyk P, Powrózek T, et al. The impact of ACE gene polymorphism on the incidence and phenotype of sarcoidosis in rural and urban settings. Arch Med Sci 2015; DOI: 10.5114/aoms.2015.48966.

15. Forth R, Montgomery H. ACE in COPD: a therapeutic target? Thorax 2003; 58: 556-8.

16. Spruit MA, Singh SJ, Garvey C, et al.; ATS/ERS Task Force on Pulmonary Rehabilitation. An official American Thoracic Society/European Respiratory Society statement: key concepts and advances in pulmonary rehabilitation. Am J Respir Crit Care Med 2013; 180: e13-64.

17. Sayed-Tabatabaei FA, Oostra BA, Isaacs A, van Duijn CM, Witteman JC. ACE polymorphisms. Circ Res 2006; 98: 1123-33.

18. Busquets X, MacFarlane NG, Heine-Suñer D, et al. Angiotensin-converting-enzyme gene polymorphisms, smoking and chronic obstructive pulmonary disease. Int J Chron Obstruct Pulmon Dis 2007; 2: 329-34.

19. Tkácová R, Joppa P, Stancák B, Salagovic J, Misíková S, Kalina I. The link between angiotensin-converting enzyme genotype and pulmonary artery pressure in patients with COPD. Wien Klin Wochenschr 2005; 117: 210-4.

20. Zhang X, Wang C, Dai H, Lin Y, Zhang J. Association between angiotensin-converting enzyme gene polymorphisms and exercise performance in patients with COPD. Respirology 2008; 13: 683-8.

21. Li X, Wei N, Wu Z, et al. The D/I polymorphism in the angiotensin-converting enzyme gene and chronic obstructive pulmonary disease risk: a meta-analysis. COPD 2012; 9: 485-91.

22. Li W, Lan F, Yan F, Shen H. Angiotensin-converting enzyme I/D polymorphism is associated with COPD risk in Asian population: evidence from a meta-analysis. COPD 2013; 10: 35-9.

23. Lee J, Nordestgaard BG, Dahl M. Elevated ACE activity is not associated with asthma, COPD, and COPD co-morbidity. Respir Med 2009; 103: 1286-92.

24. Shaw JG, Dent AG, Passmore LH, et al. Genetic influences on right ventricular systolic pressure (RVSP) in chronic obstructive pulmonary disease (COPD). BMC Pulm Med 2012; 12: 25.

25. Celli BR. Predictors of mortality in COPD. Respir Med 2010; 104: 773-9.

26. Anzueto A. Impact of exacerbations on COPD. Eur Respir Rev 2010; 19: 113-8.

27. Pitta F, Troosters T, Spruit MA, Probst VS, Decramer M, Gosselink R. Characteristics of physical activities in daily life in chronic obstructive pulmonary disease. Am J Respir Crit Care Med 2005; 171: 972-7. 